131

31

\section{RENAL DENERVATION FOR RESISTANT HYPERTENSION: SAFETY AND RESPONSE RATE AT 6 MONTHS IN A UK POPULATION}

\section{A E Amy, ${ }_{1}$ L E K Ratcliffe, ${ }^{2}$ E C Hart, ${ }^{2}$ L 0 Stewart, ${ }^{2}$ A Baumbach, ${ }^{1}$ J F R Paton, ${ }^{2}$ A K Nightingale ${ }^{1}{ }^{1}$ Bristol Heart Institute; ${ }^{2}$ University of Bristol}

\section{doi:10.1136/heartjnl-2013-304019.131}

Introduction Renal denervation (RDN) is a new, safe but expensive interventional treatment for patients with resistant hypertension. The early studies have shown a high response rate $(>10 \mathrm{~mm} \mathrm{Hg}$ drop in systolic BP) in up to $84 \%$ at 6 months. Whether this can be extrapolated to a UK population is unknown.

Methods Patients with a clinic blood pressure (cBP) of $>160 \mathrm{~mm} \mathrm{Hg}$ despite taking $\geq 3$ antihypertensive medications were identified from a specialist hypertension clinic in the South-West of England as eligible for RDN. Prior to treatment secondary causes of hypertension were excluded and magnetic resonance angiography (MRA) performed to ensure suitable renal artery anatomy. RDN was performed under conscious sedation using a Symplicity (Medtronic) ablation catheter. Patients reviewed at 1, 3, 6 and 12 months post RDN with measurement of $\mathrm{CBP}$ and renal function (estimated glomerular filtration rate, eGFR). MRA was repeated 6 months to assess for development of renal artery stenosis.

Results 13 patients underwent RDN with a mean of $5.6 \pm 0.2$ ablations per artery (range 4-8).

Table 1

\begin{tabular}{|c|c|c|c|c|}
\hline \multirow[b]{2}{*}{ Demographics } & \multirow{2}{*}{$\begin{array}{l}\text { Baseline } \\
\text { All Patients } \\
(\mathrm{n}=13)\end{array}$} & \multicolumn{3}{|c|}{$\begin{array}{l}\text { Baseline characteristics by BP response at } \\
1 \text { month }\end{array}$} \\
\hline & & $\begin{array}{l}\text { Responders } \\
(\mathrm{n}=7)\end{array}$ & $\begin{array}{l}\text { Non-responders } \\
(n=6)\end{array}$ & $\mathbf{p}=$ \\
\hline Age (years) & $56.9 \pm 3.4$ & $59.0 \pm 4.5$ & $54.5 \pm 5.4$ & 0.53 \\
\hline Male gender & $46 \%(6 / 13)$ & $29 \%(2 / 7)$ & $67 \%(4 / 6)$ & 0.04 \\
\hline eGFR (ml/min/1.73 $\left.\mathrm{m}^{2}\right)$ & $69.3 \pm 5.1$ & $66.3 \pm 5.7$ & $72.8 \pm 9.4$ & 0.57 \\
\hline $\mathrm{BMI}\left(\mathrm{kg} / \mathrm{m}^{2}\right)$ & $32.7 \pm 1.8$ & $33.0 \pm 2.5$ & $32.5 \pm 2.9$ & 0.89 \\
\hline Number of medications & $5.6 \pm 0.6$ & $5.1 \pm 0.7$ & $6.2 \pm 1.1$ & 0.44 \\
\hline $\begin{array}{l}\text { Systolic blood pressure } \\
(\mathrm{mmHg})\end{array}$ & $189.6 \pm 5.7$ & $197.1 \pm 9.7$ & $180.8 \pm 2.7$ & 0.15 \\
\hline $\begin{array}{l}\text { Diastolic blood pressure } \\
(\mathrm{mmHg})\end{array}$ & $99.0 \pm 4.5$ & $98.0 \pm 5.1$ & $100.2 \pm 8.2$ & 0.84 \\
\hline
\end{tabular}

Change in Systolic Blood Pressure Post RDN

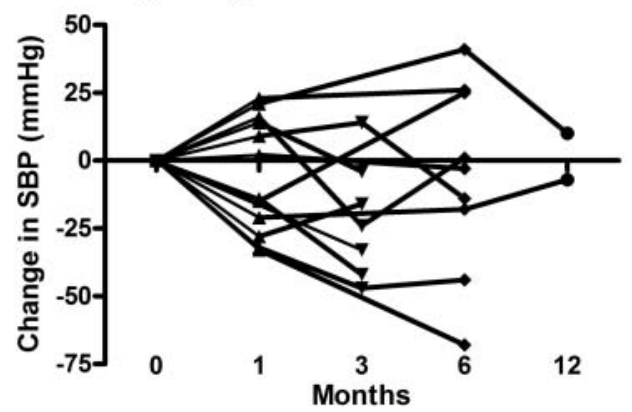

Figure 1

At 1 month post $\mathrm{RDN} 54 \%$ (7/13) of patients had responded (BP reduction of $>10 \mathrm{~mm} \mathrm{Hg}$ ), falling to $44 \%$ (4/9) of patients at 6 months.

The mean change in BP (all patients) was $-4.8 \pm 6.1 \mathrm{~mm} \mathrm{Hg}$ at 1 month and $-6.0 \pm 11.6 \mathrm{~mm} \mathrm{Hg}$ at 6 months. In the patients that responded to RDN at 1 month, the mean reduction in BP was -23.8 $\pm 3.4 \mathrm{~mm} \mathrm{Hg}$ at 1 month and $-36.0 \pm 12.6 \mathrm{~mm} \mathrm{Hg}$ at 6 months. Following RDN 1 patient experienced a drop in CBP associated with postural hypotensive symptoms; all antihypertensive medications were discontinued, but a subsequent rise in $\mathrm{cBP}$ allowed careful reintroduction of drug therapy. There were no other procedural-related adverse events. There was no significant change in mean eGFR. MRA at 6 months did not demonstrate the development of renal artery stenosis post RDN. All data presented as mean \pm SE of mean.

Conclusions Our results reinforce the finding that whilst RDN provides a significant improvement in $\mathrm{CBP}$ in some patients, a significant proportion of those treated will fail to respond. Great care is needed in monitoring $\mathrm{BP}$ following the procedure prior to restarting antihypertensive medication. Further research to establish evidence of sympathetic over-activity as a therapeutic target prior to RDN may be useful in predicting responders. Outcomes of procedural success will also be important to establish cause of potential failure to respond to RDN. 